\title{
Nanomaterials in Biology
}

\author{
Anjali Awasthi ${ }^{1} \cdot$ Kumud Kant Awasthi $^{2}$ - P. J. John ${ }^{1}$
}

Published online: 11 March 2021

(C) The Author(s), under exclusive licence to Springer-Verlag GmbH Germany, part of Springer Nature 2021

Nanomaterials (nanoparticles, nanowires, nanofibers, nanotubes) have opened up new dimensions in science and technology and created new opportunities in many biological applications (biosensing, biological separation, molecular imaging, anticancer therapy). All biological and man-made systems have the first level of organization at the nanoscale (such as nanocrystal, nanotubes or nanobiomotors) where their fundamental properties and functions are defined. Nanotechnology provides the tools and technology platforms for the investigation and transformation of biological systems, and biology offers inspiration models and bio-assembled components to nanotechnology. These features have been providing the impetus to discover unknown physical and chemical properties of newer materials by precisely controlling their structure and composition for tailor-made technological applications.

To provide a platform for comprehensive dissemination of knowledge and exchange of ideas among the academicians, scientists and industry professionals, a multidisciplinary national conference on Nanomaterials in Biology (NCNB 2019) was organized by Soft Materials Research Society Jaipur and Department of Zoology, University of Rajasthan, Jaipur, India, during 9-12 October 2019, in which application of nanomaterials in biology was one of the important themes.

We have great pleasure in presenting this special issue in Environmental Science and Pollution Research (ESPR) from the selected papers of NCNB 2019. The conference was organized in the following topics: Engineered nanomaterials,

Responsible Editor: Philippe Garrigues

Anjali Awasthi

anjkam.awasthi@gmail.com

1 Department of Zoology, University of Rajasthan, Jaipur, Rajasthan, India

2 Department of Life Sciences, Vivekananda Global University, Jaipur, Rajasthan, India
Nanomaterials in medicine and therapeutics, Nanosystems for 3D models and tissue engineering, Nanoimaging for diagnosis and detection, Biological nanodevices and biosensors, Bioinspired and biomimetic materials, Nanomaterials in agriculture, Nanotechnology in gene delivery, Nanomaterials and environmental effects, Biological uptake and Nanotoxicology.

The inaugural note was delivered by Prof. Udaykumar R. Yaragatti (Director, MNIT, Jaipur, and President, SMRS, Jaipur). The conference was a great success with 20 invited speakers and 108 participants from different geographical regions of India covering every aspect of nanoamterial applications in biology. This conference was multidisciplinary and provided a forum for exchange of latest technical information, dissemination of high-quality research results on the issues related to nanomaterials and their applications in Biology. Networking promoted by this workshop helped to create a sustainable partnership of research and industry working in these areas. We were successful to bring together a multidisciplinary group of scientists.

At this place, we thank all the contributing authors and are deeply indebted to the numerous reviewers for the detailed review. Special appreciation to Prof. Philippe Garrigues, Editor-in-Chief, for his great support and efforts. We highly appreciate the time to time assistance provided by Ms. Florence Delavaud and the entire editorial, publishing and production teams of the Environmental Science and Pollution Research for their considerable efforts in bringing out this issue. In addition, we are deeply indebted to all the people that contributed to the success of this conference and to this special issue. We do hope that this special issue, NCNB 2019 , provides valuable insights to the researchers working in the area of nano-biotechnology.

Guest Editors

Anjali Awasthi, Kumud Kant Awasthi and P J John

Publisher's note Springer Nature remains neutral with regard to jurisdictional claims in published maps and institutional affiliations. 


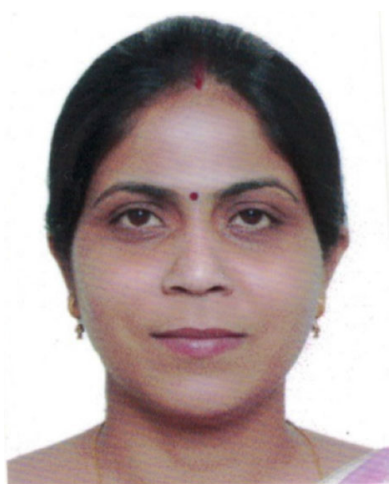

Dr. Anjali Awasthi is currently working as Assistant Professor at Department of Zoology, Centre for Advanced Studies, University of Rajasthan, Jaipur. She has completed M.Sc., M. Phil (Zoology) from Dr. B. R. Ambedkar University Agra and Ph.D. (Biotechnology) from Indian Institute of Technology, Roorkee, India. Her area of research is Molecular Biology and Nano biotechnology. She has a vast experience in the field of toxicity assessment for different nanomaterials in different in vivo and in vitro models as well as on biosensor development and biofouling studies of nanomaterials. She is guiding Ph.D. and M. Tech scholars for their degrees. She is a life member of esteemed scientific national and international societies. Dr. Awasthi is also a nominated member of CPCSEA, Ministry of Environment Forest \& Climate Change Govt. of India. She is a recipient of Young Scientist Award by the Department of Science and Technology, Govt. of India. She is a reviewer of different journals and has organized many International and National Conferences

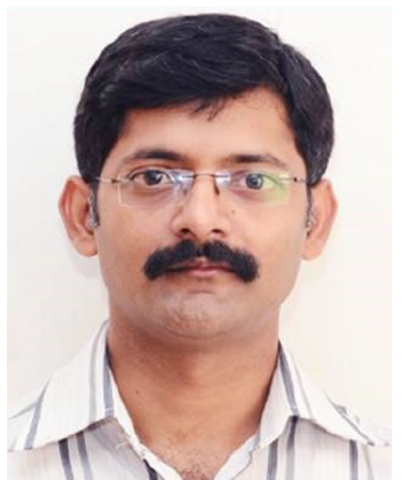

Dr. Kumud Kant Awasthi is currently working as Associate Professor and Head of the Department of Life Sciences, Vivekananda Global University, Jaipur. He has served at the National Institute of Animal Welfare, Faridabad, India. Dr. Awasthi completed M.Sc. (Zoology) and Ph.D. from the University of Rajasthan, Jaipur, India. His area of research is environmental toxicology with reference to nanoparticles. He has a vast experience in the field of toxicity assessment for different nanomaterials in different in vivo and in vitro models and their safe use for drug development. He is guiding $\mathrm{Ph} . \mathrm{D}$. scholars for their degrees. He is a life member of esteemed scientific national and international societies viz., STOX, ISCA, MRSI, ISLS, ISID, ESTIV, SMRS and also a nominated member of the committee for the ethical use of laboratory animals in research by CPCSEA, Ministry of Environment Forest \& Climate Change, Govt. of India. He is constantly involved in research activity as a member of editorial boards, reviewers of different journals and organizing committees of national and international conferences.

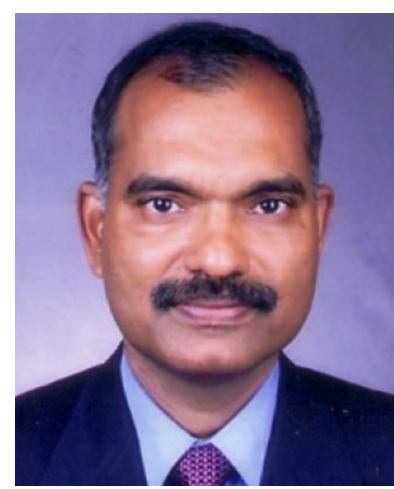

Dr. P. J. John is currently working as Associate Professor and Head of the Department of Zoology, Centre for Advanced Studies, Department of Zoology, University of Rajasthan (UOR), Jaipur, India, and having more than 28 years of teaching and research experience in the area of Environmental Biology and Nanotechnology. Dr. John is holding many other responsibilities of the University viz, Hony. Director, P.G. School of Life Science; Coordinator, PG Courses in Microbiology; Deputy Chief-Coordinator, University Innovation Cluster in Biotechnology; Joint Director, Cognitive and Neurosciences; CCT; Co-coordinator, MHRD's Innovation Cell, UOR, Jaipur. Dr. John has guided 23 scholars for Ph.D. programme and four scholars for their post-doctoral research work and published more than 80 research articles, review articles, book chapters, books, monograph, editorial, etc. Dr. John is a Fellow of the Society of Toxicology, (FST) and of the Academy of Environmental Biology, (F.A.E.B.). He is a recipient of several awards at the national and international levels as Global Senior Scholar Exchange Program (GSSEP) Award from Society of Toxicology (SOT), USA, DAAD Fellowship, German Academic Exchange Service, Bonn, Germany. 